Article

\title{
Predicting the Failure of Dental Implants Using Supervised Learning Techniques
}

\author{
Chia-Hui Liu ${ }^{1,2, \dagger}$, Cheng-Jyun Lin ${ }^{3, \dagger}$, Ya-Han $\mathrm{Hu}^{2,4}$ and Zi-Hung You ${ }^{5, * \text { (D) }}$ \\ 1 Department of Nursing, Ditmanson Medical Foundation Chia-Yi Christian Hospital, Chiayi 600, Taiwan; \\ 02217@cych.org.tw \\ 2 Department of Information Management and Institute of Healthcare Information Management, \\ National Chung Cheng University, Chiayi 621, Taiwan; yahan.hu@mis.ccu.edu.tw \\ 3 Department of Dentistry, Ditmanson Medical Foundation Chia-Yi Christian Hospital, Chiayi 600, Taiwan; \\ s03530015@ccu.edu.tw \\ 4 Center for Innovative Research on Aging Society, National Chung Cheng University, Chiayi 621, Taiwan \\ 5 Department of Nephrology, Chiayi Branch, Taichung Veterans General Hospital, Chiayi 600, Taiwan \\ * Correspondence: zihing.you@gmail.com \\ + These authors contributed equally.
}

Received: 6 April 2018; Accepted: 27 April 2018; Published: 2 May 2018

\begin{abstract}
Prosthodontic treatment has been a crucial part of dental treatment for patients with full mouth rehabilitation. Dental implant surgeries that replace conventional dentures using titanium fixtures have become the top choice. However, because of the wide-ranging scope of implant surgeries, patients' body conditions, surgeons' experience, and the choice of implant system should be considered during treatment. The higher price charged by dental implant treatments compared to conventional dentures has led to a rush among medical staff; therefore, the future impact of surgeries has not been analyzed in detail, resulting in medial disputes. Previous literature on the success factors of dental implants is mainly focused on single factors such as patients' systemic diseases, operation methods, or prosthesis types for statistical correlation significance analysis. This study developed a prediction model for providing an early warning mechanism to reduce the chances of dental implant failure. We collected the clinical data of patients who received artificial dental implants at the case hospital for a total of 8 categories and 20 variables. Supervised learning techniques such as decision tree (DT), support vector machines, logistic regressions, and classifier ensembles (i.e., Bagging and AdaBoost) were used to analyze the prediction of the failure of dental implants. The results show that DT with both Bagging and Adaboost techniques possesses the highest prediction performance for the failure of dental implant (area under the receiver operating characteristic curve, AUC: 0.741); the analysis also revealed that the implant systems affect dental implant failure. The model can help clinical surgeons to reduce medical failures by choosing the optimal implant system and prosthodontics treatments for their patients.
\end{abstract}

Keywords: artificial dental implant surgery; data mining; dental implant failure; supervised learning techniques

\section{Introduction}

Artificial dental implants have been in development for nearly 60 years, and under the constant research and improvements of clinicians and scholars [1]. Most artificial prosthesis implant systems include three parts: fixtures, abutments, and prostheses. A fixture is used to replace the natural root of the tooth and form osseointegration with the edentulous ridge; an abutment is used to connect the structures of the fixture and prosthesis; and the prosthesis is used to replace the natural tooth crown 
for occlusion and aesthetic functions. The treatment can be divided into two stages: in the first stage, the fixture is surgically implanted into the alveolar bone; after osseointegration is completed three to six months later, the second stage (prosthodontic treatment) is executed. The treatment is completed after the abutment and prosthesis are connected to the fixture.

In most studies, the success criteria for dental implants are based on the standards proposed by Albrektsson et al. (1986) [2].

- The X-ray film shows no signs of radiolucency in the alveolar bone around the fixture.

- Alveolar bone resorption around the fixture does not exceed $1 \mathrm{~mm}$ within the first year after the dental implant.

- The annual bone loss around the fixture does not exceed $0.2 \mathrm{~mm}$.

According to the fixture quality stipulated during the 2007 consensus conference by the International Congress of Oral Implantologists, dental implant failure is defined as follows [3].

- Pain and shakiness during occlusion.

- Bone loss does not exceed half the fixture length under X-ray.

- Uncontrollable exudation around the implant.

- The implant is no longer in the mouth.

Previous studies have revealed many factors affecting the failure of dental implants, including individual patient factors, the location of the implant, bone density, fixture, prosthodontics factors, the implant surgery method, implant timing, and the skew angle of the abutment [4-7]. In addition, because implant treatments involve delicate surgical stages, the clinical surgeons' training backgrounds and their surgical operation experience are key factors directly affecting successful treatments; however, currently only two studies have mentioned their relationships to implant treatment results [8,9]. Furthermore, the two main abutment and crown fixation methods are cementing and screw-retention. Most clinical physicians select the appropriate approach according to their clinical experience and the conditions of each specific case. The current literature only mentions that both methods display the same clinical adhesiveness, without otherwise comparing their benefits and drawbacks, or chances of failure.

Supervised learning techniques have been extensively used in medical applications, and are also often used in dentistry for result forecasts to reduce treatment failures and medical resource wastage [10-12]. Bouchard et al. (2009) used a decision tree (DT) exploration and stratification approach to compare the practical utility analysis of conventional dental bridges and artificial dental implants, to provide a reference for clinical physicians and patients [13]. To analyze implant success and failure evaluations, Chiang et al. (2013) conducted a retrospective study using C5.0 DT to analyze the critical factors of implant surgeries. A total of 1161 fixtures from 513 patients at three dental clinics were collected [14]. The results demonstrated a 0.825 sensitivity and a 0.992 specificity; prosthodontists can predict results of dental implant surgery based on a patients' physical status and implant characteristics by the DT classifier. Bone density was the most important factor, followed by the angle of implant abutment, dialysis, and implant length/width.

Previous studies mostly focus on dental implant failure after all the implant treatments are completed [15]. In this study, we develop prediction models in which failure predictions are conducted for the time after prosthodontics treatment. We used demographic information, as well as the fixture and prosthesis information collected clinically from patients with dental implants, combined with general statistics and supervised learning techniques to analyze the potential factors affecting dental implant failure. The prediction models were then established to assist in reducing the chances of subsequent complications; the models also enable clinical physicians to forecast the failure rate of dental implants, as well as to develop treatment improvement measures in advance to improve treatment in the event of implant failure [16]. 


\section{Materials and Methods}

\subsection{Data}

This research uses the clinical data of patients who received dental implants at the dentistry department of the Chia-Yi Christian Hospital. However, because hospital medical records involved patients' private information, the study protocol was approved by the Chia-Yi Christian Hospital Institutional Review Board (CYCH-IRB No. 105009). Written consent from the study was deemed unnecessary, because the dataset comprises only de-identified secondary data for research purposes, and the Chia-Yi Christian Hospital Institutional Review Board issued a formal written waiver of the need for consent and approved the study.

The data sampling time was from January 2005 to December 2015. The necessary information was collected from electronic medical records, dental implant surgery records, prosthodontics treatment records, and digital X-ray interpretation using a retrospective approach. To avoid affecting the experimental results, most factors that have been verified in the literature to cause fixture failures were excluded, including patients who have undergone head and neck radiotherapy, patients with long term use or injection of bisphosphonate drugs, and patients who did not return to complete their treatment.

The clinical data for this study came from 681 patients for a total of 1034 fixture implants, of which 13 were removed completely because of implant failures, thus achieving a $98.75 \%$ survival rate. A number of patients did not complete the subsequent prosthodontics treatment after their implant surgeries for individual reasons. As a result, a total of 747 fixtures from patients who completed their prosthodontics treatments were recorded, of which 361 fixtures belonged to men, and 385 to women.

\subsection{Variable}

The dependent variable is dental implant failure, which can be determined by checking whether patients have fulfilled the success criteria proposed by Albrektsson (1986) 4 to 12 months after the operation [2]. The investigated independent variables are shown in Table 1, which were mainly drawn from the literature and the research goals of this study. They are divided into 8 categories for a total of 20 variables, which include age, gender, factors of missing, systemic disease, tobacco smoking, alcohol consumption, betel nut chewing, department of surgeon, surgeon experience, location of implant, bone density, ridge augmentation, Maxillary sinus augmentation, implant system, fixture length, fixture width, types of prosthesis, angle of abutment, and prosthesis fixation.

Table 1. Definition of variables.

\begin{tabular}{lll}
\hline Group & Independent Variables & Definition and Code \\
\hline \multirow{3}{*}{ Demographics } & Age & Ratio scale \\
\cline { 2 - 3 } & Gender & $0:$ Female \\
& 1: Male \\
\hline & 0: Healthy \\
& 1: Cardiovascular disorder \\
& 2: Diabetes \\
& 3: Osteoporosis \\
& & $4:$ Radiotherapy \\
\cline { 2 - 3 } Physical condition & 5: Others \\
& & $0:$ Congenital missing \\
& 1: Caries \\
& 2: Periodontitis \\
& Factors of missing & 4: Root resorption \\
& 5: Failure of endodontic treatment \\
\hline
\end{tabular}


Table 1. Cont.

\begin{tabular}{|c|c|c|}
\hline Group & Independent Variables & Definition and Code \\
\hline \multirow{3}{*}{ Lifestyle } & Tobacco smoking & $\begin{array}{l}0: \text { Never } \\
\text { 1: Smoking } \\
\text { 2: Stopped smoking }\end{array}$ \\
\hline & Betel nut chewing & $\begin{array}{l}0: \text { Never } \\
\text { 1: Chewing betel nut } \\
\text { 2: Stopped chewing betel nut }\end{array}$ \\
\hline & Alcohol consumption & $\begin{array}{l}0: \text { Never } \\
\text { 1: Drinking } \\
\text { 2: Stopped drinking }\end{array}$ \\
\hline \multirow[t]{2}{*}{ Surgeon Background } & Departments & $\begin{array}{l}\text { 0: General practice } \\
\text { 1: Periodontics } \\
\text { 2: Oral-Maxillary surgery }\end{array}$ \\
\hline & Surgeon experience & Ratio scale \\
\hline \multirow[t]{2}{*}{ Anatomic Condition } & Location of implant & $\begin{array}{l}\text { 0: Maxillary anterior teeth } \\
\text { 1: Maxillary premolars } \\
\text { 2: Maxillary molars } \\
\text { 3: Mandibular anterior teeth } \\
\text { 4: Mandibular premolars } \\
\text { 5: Mandibular molars }\end{array}$ \\
\hline & Bone density & $\begin{array}{l}\text { 1: Type I } \\
\text { 2: Type II } \\
\text { 3: Type III } \\
\text { 4: Type IV }\end{array}$ \\
\hline \multirow{3}{*}{ Surgical Information } & Timing of implant placement & $\begin{array}{l}\text { 1: Immediate implant placement } \\
\text { 2: Early implant placement } \\
\text { 3: Staged implant placement }\end{array}$ \\
\hline & Ridge augmentation & $\begin{array}{l}0: \text { None } \\
\text { 1:Guided bone regeneration } \\
\text { 2: Ridge splitting }\end{array}$ \\
\hline & Maxillary sinus augmentation & $\begin{array}{l}\text { 0: None } \\
\text { 1: Lateral window technique } \\
\text { 2: Osteotome technique }\end{array}$ \\
\hline \multirow[t]{3}{*}{ Implant attributes } & Implant system & $\begin{array}{l}\text { 0: Straumann }{ }^{\circledR} \\
\text { 1: Ankylos } \\
\text { 2: } \text { XIVE }^{\circledR} \\
\text { 3: Nobeactive }{ }^{\circledR} \\
\text { 4: Branemark } \\
\text { 5: Lifecore }{ }^{\circledR}\end{array}$ \\
\hline & Fixture length & Ratio scale \\
\hline & Fixture width & Ratio scale \\
\hline \multirow{3}{*}{ Prosthetics attributed } & Types of prosthesis & $\begin{array}{l}0: \text { Fixed denture } \\
1 \text { : Overdenture }\end{array}$ \\
\hline & Angle of abutment & $\begin{array}{l}0: \text { Without angle } \\
\text { 1: With angle }\end{array}$ \\
\hline & Prosthesis fixation & $\begin{array}{l}\text { 0: Cement-retained } \\
\text { 1: Screw-reained }\end{array}$ \\
\hline
\end{tabular}

\subsection{Statistical Analysis Tools}

The chi-square test was employed for independent categorical variables, whereas the Mann-Whitney $U$ test or independent samples $t$-test were adopted for continuous variables for significant analysis. The data processing was analyzed and presented using SPSS (Version 20.0, IBM Corp, Armonk, NY, USA, 2011).

The data mining software WEKA (Version 3.8.1, Machine Learning Group at the University of Waikato, Hamilton, Waikato, New Zealand, 2017) was used to construct the prediction models for three 
single classifiers: C4.5 decision tree (DT), logistic regression (LGR), and support vector machine (SVM). In addition, two classifier ensembles techniques (i.e., Bagging and AdaBoost) were also considered to improve the prediction performance of the three single classifiers [17-19]. To avoid the class imbalance problem, we performed ClassBalancer module in WEKA 3.8.1 to reweight the samples so that each class had the same total weight during the phase of model training [20]. Ten-fold cross-validation was then adopted to verify the predictive mode performance, followed by the evaluation of the performance of various prediction models using a confusion matrix (Table 2).

Table 2. Confusion matrix.

\begin{tabular}{|c|c|c|}
\hline $\begin{array}{ll}\text { Predicted Classes } & \text { Actual Classes } \\
\end{array}$ & Dental ImplantFailure & Dental ImplantSuccess \\
\hline Dental implantfailure & $\mathrm{TP}$ & $\mathrm{FN}$ \\
\hline Dental implantsuccess & $\mathrm{FP}$ & $\mathrm{TN}$ \\
\hline
\end{tabular}

In Table 2, TP represents the number of failure implant surgeries that were predicted to fail, $\mathrm{TN}$ represents the number of success surgeries that were predicted to succeed, FP represents the number of successful surgeries that were predicted to fail, and FN represents the number of failure surgeries that were predicted to be succeed. Finally, the forecast capacities of each prediction model were assessed through sensitivity, specificity, accuracy, and area under the receiver operating characteristic curve (AUC). Sensitivity refers to the ratio of dental implant failure correctly predicted by the model in the actual implant failure group, specificity is the ratio of dental implant success correctly predicted by the model in the actual implant success group, and accuracy refers to the percentage of the correctly predicted results. To establish prediction models, we used a feature selection module, named GainRatioAttributeEval, in WEKA to identify important independent variables.

\section{Results}

\subsection{Descriptive Statistics}

The statistical results of categorical variables (Table 3) showed that alcohol consumption $(p<0.05)$, factor of missing $(p<0.05)$, implant location $(p<0.01)$, ridge augmentation $(p<0.001)$, and the implant system $(p<0.001)$ were statistically significant. The continuous variables for late implant failure are as described earlier. The statistics were subjected to an independent sampled $t$-test, revealing that fixture width was significantly correlated $(p<0.05)$ to implant failure.

Table 3. Descriptive statistics.

\begin{tabular}{|c|c|c|c|c|c|}
\hline \multirow{2}{*}{ Variable } & \multicolumn{2}{|c|}{ Success $n=630(84.3 \%)$} & \multicolumn{2}{|c|}{ Failure $n=117(15.7 \%)$} & \multirow{2}{*}{$p$ Value } \\
\hline & Num. & $\%$ & Num. & $\%$ & \\
\hline \multicolumn{5}{|c|}{ Gender } & \multirow[t]{3}{*}{0.573} \\
\hline 0 & 334 & $44.7 \%$ & 52 & $7.0 \%$ & \\
\hline 1 & 296 & $39.6 \%$ & 65 & $8.2 \%$ & \\
\hline \multicolumn{5}{|c|}{ Systemic disease } & \multirow[t]{7}{*}{0.165} \\
\hline 0 & 434 & $58.1 \%$ & 82 & $11.0 \%$ & \\
\hline 1 & 124 & $16.6 \%$ & 21 & $2.8 \%$ & \\
\hline 2 & 20 & $2.7 \%$ & 7 & $0.9 \%$ & \\
\hline 3 & 5 & $0.7 \%$ & 1 & 0.1 & \\
\hline 4 & 0 & $0 \%$ & 0 & $0 \%$ & \\
\hline 5 & 47 & $6.3 \%$ & 6 & $0.8 \%$ & \\
\hline \multicolumn{5}{|c|}{ Factors of missing } & \multirow[t]{7}{*}{0.541} \\
\hline 0 & 0 & 0 & 1 & $0.1 \%$ & \\
\hline 1 & 174 & $23.5 \%$ & 26 & $3.5 \%$ & \\
\hline 2 & 290 & $39.1 \%$ & 68 & $9.2 \%$ & \\
\hline 3 & 144 & $19.4 \%$ & 20 & $2.7 \%$ & \\
\hline 4 & 1 & $0.1 \%$ & 1 & $0.1 \%$ & \\
\hline 5 & 15 & $2.0 \%$ & 1 & $0.1 \%$ & \\
\hline
\end{tabular}


Table 3. Cont.

\begin{tabular}{|c|c|c|c|c|c|}
\hline \multirow{2}{*}{ Variable } & \multicolumn{2}{|c|}{ Success $n=630(84.3 \%)$} & \multicolumn{2}{|c|}{ Failure $n=117(15.7 \%)$} & \multirow{2}{*}{$p$ Value } \\
\hline & Num. & $\%$ & Num. & $\%$ & \\
\hline \multicolumn{5}{|c|}{ Tobacco smoking } & \multirow[t]{4}{*}{0.362} \\
\hline 0 & 497 & $70.6 \%$ & 96 & $13.1 \%$ & \\
\hline 1 & 73 & $8.2 \%$ & 12 & $1.5 \%$ & \\
\hline 2 & 36 & $5.9 \%$ & 5 & $0.7 \%$ & \\
\hline \multicolumn{5}{|c|}{ Alcohol consumption } & \multirow[t]{4}{*}{0.106} \\
\hline 0 & 541 & $76.8 \%$ & 105 & $14.4 \%$ & \\
\hline 1 & 52 & $6.5 \%$ & 3 & $0.4 \%$ & \\
\hline 2 & 13 & $1.4 \%$ & 5 & $0.5 \%$ & \\
\hline \multicolumn{5}{|c|}{ Betel nut chewing } & \multirow[t]{4}{*}{$0.014 *$} \\
\hline 0 & 582 & $79.9 \%$ & 108 & $14.5 \%$ & \\
\hline 1 & 12 & $1.4 \%$ & 5 & $0.6 \%$ & \\
\hline 2 & 12 & $3.5 \%$ & 0 & $0.02 \%$ & \\
\hline \multicolumn{5}{|c|}{ Departments } & \multirow[t]{4}{*}{0.389} \\
\hline 0 & 188 & $18.6 \%$ & 43 & $4.2 \%$ & \\
\hline 1 & 353 & $34.8 \%$ & 63 & $6.2 \%$ & \\
\hline 2 & 317 & $31.3 \%$ & 49 & $4.8 \%$ & \\
\hline \multicolumn{5}{|c|}{ Location of implant } & \multirow{7}{*}{$0.004^{* *}$} \\
\hline 0 & 106 & $12.0 \%$ & 35 & $1.9 \%$ & \\
\hline 1 & 141 & $14.6 \%$ & 14 & $0.8 \%$ & \\
\hline 2 & 164 & $18.0 \%$ & 26 & $0.9 \%$ & \\
\hline 3 & 53 & $5.4 \%$ & 11 & $0.8 \%$ & \\
\hline 4 & 91 & $9.6 \%$ & 19 & $1.4 \%$ & \\
\hline 5 & 303 & $32.2 \%$ & 50 & $2.3 \%$ & \\
\hline \multicolumn{5}{|c|}{ Bone density } & \multirow[t]{5}{*}{0.96} \\
\hline 1 & 1 & $0.1 \%$ & 0 & $0 \%$ & \\
\hline 2 & 238 & $32.0 \%$ & 40 & $5.4 \%$ & \\
\hline 3 & 345 & $46.4 \%$ & 60 & $8.1 \%$ & \\
\hline 4 & 46 & $6.2 \%$ & 13 & $1.7 \%$ & \\
\hline \multicolumn{5}{|c|}{ Timing of implant placement } & 0.289 \\
\hline 1 & 17 & $2.3 \%$ & 1 & $0.1 \%$ & \\
\hline 2 & 553 & $74.7 \%$ & 100 & $13.5 \%$ & \\
\hline 3 & 53 & $7.2 \%$ & 16 & $2.2 \%$ & \\
\hline & & ugment & & & $0.000^{* * *}$ \\
\hline 0 & 397 & $54.2 \%$ & 48 & $6.6 \%$ & \\
\hline 1 & 213 & $29.1 \%$ & 62 & $8.5 \%$ & \\
\hline 2 & 12 & $1.6 \%$ & 0 & $0 \%$ & \\
\hline & Maxi & hus augr & tation & & 0.336 \\
\hline 0 & 529 & $72.3 \%$ & 101 & $13.8 \%$ & \\
\hline 1 & 39 & $5.3 \%$ & 1 & $0.1 \%$ & \\
\hline 2 & 54 & $7.4 \%$ & 8 & $1.1 \%$ & \\
\hline & & ant syste & & & $0.000^{* * *}$ \\
\hline 0 & 394 & $52.7 \%$ & 44 & $5.9 \%$ & \\
\hline 1 & 155 & $20.7 \%$ & 52 & $7.0 \%$ & \\
\hline 2 & 27 & $3.6 \%$ & 8 & $1.1 \%$ & \\
\hline 3 & 17 & $2.3 \%$ & 10 & $1.3 \%$ & \\
\hline 4 & 18 & $2.4 \%$ & 1 & $0.1 \%$ & \\
\hline 5 & 19 & $2.5 \%$ & 2 & $0.3 \%$ & \\
\hline & & of prosth & & & 0.019 * \\
\hline 0 & 585 & $78.7 \%$ & 106 & $14.2 \%$ & \\
\hline 1 & 42 & $5.6 \%$ & 10 & $1.3 \%$ & \\
\hline & & of abutm & & & 0.858 \\
\hline 0 & 548 & $73.8 \%$ & 91 & $12.2 \%$ & \\
\hline 1 & 78 & $10.5 \%$ & 21 & $2.8 \%$ & \\
\hline & & esis fixat & & & 0.027 * \\
\hline 0 & 525 & $70.9 \%$ & 88 & $11.9 \%$ & \\
\hline 1 & 102 & $13.8 \%$ & 26 & $3.5 \%$ & \\
\hline
\end{tabular}




\subsection{Experimental Results for the Prediction Model}

A total of 630 fixtures in this study were dental implant successes, whereas only 117 were dental implant failures, yielding a failure ratio of $15.7 \%$. The performance of each classifier is summarized in Table 4. The results show that classifier ensembles (i.e., both Bagging and AdaBoost) techniques can improve prediction performance of the investigated three single classifiers; the single classifiers with Bagging technique perform slightly better than those with Adaboost technique. The Bagging + DT had the best prediction performance, which indicated 0.581 sensitivity for the correct prediction of the dental implant failure and 0.822 specificity for the correct prediction of the dental implant success. The overall Bagging + DT model had a prediction accuracy of 0.702, and a further prediction performance assessment showed 0.741 AUC. The Bagging + LGR results demonstrated 0.573 sensitivity and 0.678 specificity. The overall Bagging + LGR model had a prediction accuracy of 0.625 , whereas a further prediction capacity evaluation yielded 0.674 AUC. The Bagging + SVM results displayed 0.598 sensitivity and 0.640 specificity. The overall Bagging + SVM model had a prediction accuracy of 0.619 , and a further prediction capacity assessment indicated 0.670 AUC.

Table 4. Results of classification performance. DT: decision tree; LGR: logistic regression; SVM: support vector machine; AUC: area under the receiver operating characteristic curve.

\begin{tabular}{ccccc}
\hline Classifier & Accuracy & Sensitivity & Specificity & AUC \\
\hline DT & 0.679 & 0.590 & 0.768 & 0.670 \\
LGR & 0.624 & 0.607 & 0.641 & 0.644 \\
SVM & 0.628 & 0.581 & 0.675 & 0.628 \\
Bagging + DT & 0.702 & 0.581 & 0.822 & 0.741 \\
Bagging + LGR & 0.625 & 0.573 & 0.678 & 0.674 \\
Bagging + SVM & 0.619 & 0.598 & 0.640 & 0.670 \\
Adaboost + DT & 0.671 & 0.470 & 0.871 & 0.741 \\
Adaboost + LGR & 0.600 & 0.513 & 0.687 & 0.655 \\
Adaboost + SVM & 0.633 & 0.513 & 0.754 & 0.654 \\
\hline
\end{tabular}

\section{Discussion}

The importance of the investigated variables calculated by gain ratio (GainRationAttributeEval module in WEKA) is shown in Table 5. The results indicated the first six items as fixture width, implant system, betel nut chewing, ridge augmentation, fixture length, and alcohol consumption. This order also indicates the extent to which each variable attribute affects dental implant failure, with fixture width being the major influencing factor followed by the implant system and betel nut chewing.

Table 5. Importance of the variables.

\begin{tabular}{ccc}
\hline Rank & Variables & Importance \\
\hline 1 & Fixture width & 0.02446 \\
2 & Implant system & 0.02091 \\
3 & Chewing betel nut & 0.01907 \\
4 & Ridge augmentation & 0.01817 \\
5 & Fixture length & 0.01519 \\
6 & Alcohol consumption & 0.01234 \\
7 & Sinus augmentation & 0.00965 \\
8 & Location of implant & 0.00768 \\
9 & Timing of implant placement & 0.00708 \\
10 & Factors of missing & 0.00688 \\
\hline
\end{tabular}

\section{- $\quad$ Fixture Width}

Dental implants have different widths according to distinct implant locations (the anterior area, premolars, and molars), with fixture diameters ranging from $3.0 \mathrm{~mm}$ to $5.0 \mathrm{~mm}$. However, it is 
not compulsory to follow such principles for treatments, which are mostly determined by clinical physicians according to individual situations. The DT analysis employed in this study shows that late fixture failure was correlated with fixture width. Allum et al. (2008) proposed that fixture width and occlusal force area have a significant relationship, the main reason being that the occlusal force withstood by the narrow fixtures (diameter $\leq 3.5 \mathrm{~mm}$ ) is smaller, thus rendering it unsuitable for areas that require stronger occlusion [21]. In addition, the independent $t$-test in this study verified that fixture width is correlated with late fixture failure. According to Chiang et al. (2013), a one-unit increase in fixture length increases the fixture failure rate 2.9 times, indicating that fixture width plays a crucial role once the fixture is connected to the prosthesis and starts withstanding occlusion force [14].

- Implant system

Artificial fixtures are a type of medical equipment with various systems and brands on the market, and the greatest differences between them lie in fixture surface treatment, the appearance of the artificial tooth root, and the fixture and abutment connections. Fixtures have been developed and produced by conventional manufacturers such as Straumann and Nobel Biocare, and today their fixture surface treatment technology is capable of achieving long-term osseointegration success [22].

The greatest distinction in the appearance of the artificial tooth roots is that they are either columnor cone-shaped. The capacity to withstand forces is different according to distinct connections and shapes [23]. Based on a systematic literature review of medical databases, Theoharidou et al. (2008) identified 27 studies, of which 15 focused on internal connections, whereas the other 12 related to external connections. Their analysis revealed that the conditions for abutment screw loosening differed according to the connection method [24].

- Chewing betel nut and alcohol consumption

According to the conclusion of the 17th European Association of Osseointegration Congress in 2008, poor oral hygiene and lifestyle are high risk factors for peri-implantitis, and betel nut chewing and alcohol consumption are the detrimental life habits commonly seen among Taiwanese [25]. A literature review by a Hong Kong research team revealed that betel nut or tobacco chewing, like smoking, can lead to oral cancer, periodontal disease, or even dental implant failure [26]. According to Ling et al. (2001), patients who chew betel nuts are prone to periodontal pathogen (Actinobacillus actinomycetemcomitans and Porphyromonas gingivalis) hyperplasia, which manifests in clinical conditions such as gingival bleeding and periodontal bone loss, causing a considerable impact on dental implants [27]. In addition, because of the hardness of betel nuts, damage to fixtures with incomplete osseointegration during chewing can cause irreparable damage to implants.

The analysis in this study revealed that the relationship between patients' alcohol consumption habits and late fixture failure are statistically significant $(p<0.05)$, indicating that alcohol consumption affects periodontal bone loss after the occlusion of fixtures. Based on research by Galindo-Moreno et al. (2005), patients with daily alcohol consumption of up to $100 \mathrm{~g}$ have a higher fixture bone loss rate compared to those without alcohol consumption [28]. Therefore, drinking habits are indeed relevant factors for dental implant failure.

- Ridge augmentation

Ridge augmentation is a common supplementary operation in implant surgeries, which is mostly used in the event of insufficient alveolar bone width and height. This study discovered that failures occurred in $12.5 \%$ of the fixtures that underwent ridge augmentation, which echoes the guided bone regeneration risk proposed by McDermott et al. (2003) [29]. 
- Location of implant

Dental implants have differing functions and requirements according to their locations: they focus more on occlusal functions in the posterior area to grind food, whereas those in the anterior area are required for aesthetic functions. The posterior area can be divided into two locations: the premolars and molars. Parein et al. (1997) collected 392 fixtures from 152 patients, and their statistical analysis after six years of tracking revealed that single molar implant prostheses have a higher failure occurrence than premolar implant prosthesis $(p<0.001)$ [30]. The findings indicated that molars sustain a higher occlusal force compared to the premolars and thus have a greater chance of problems, up to $49.8 \%$. In addition, if a distinction is made between the upper and lower jaws, the regression analysis by McDermott et al. (2003) demonstrated that upper jaws have a higher failure rate compared to lower jaws [29]; Moy et al. (2005) also discovered that the upper jaw fixture failure rate (8.16\%) is higher than that of lower jaw fixtures $(4.93 \%)$, which is a significant difference $(p<0.001)$ [31].

According to the Manor et al. (2009), comparing the failure rates for differing implant locations in 194 patients, 6 years of tracking revealed that posterior teeth have a higher chance of failure occurrences [32]. The DT analysis in this study showed a similar result for the lower jaw premolars in the posterior area compared to those in other locations. This could be because the area is closer to the mental foramen, a crucial anatomical structure that causes difficulties for surgeons to implant fixtures in the correct position or perform ridge augmentation, thereby leading to further failure risk.

\section{Conclusions}

Supervised learning techniques have been widely applied in the medical field to search for and analyze relevant information in the medical literature to uncover key medical information that can serve clinical workers in their decision making. Therefore, this study on predicting dental implant failure was conducted using supervised learning techniques to quantify and analyze collected data. The key findings are listed below:

- Comparing the prediction performance of the three tested supervised learning techniques, the results revealed that DT is the optimal model for forecasting dental implant failure.

- Fixture width, implant system, betel nut chewing, ridge augmentation, fixture length, and alcohol consumption are the top five most influential independent variables on dental implant failure prediction.

- This study not only demonstrates the influencing factors for dental implant failure, but also extends to clinical practice for the benefit of the public. However, there are still areas in which future study can advance our understanding. The retrospective data collection adopted in this study led to a considerable lack of information, which could have affected the analysis results; prospective research methods should be adopted in future work to collect more complete information, enabling the correctness of the analysis results to be closer to actual clinical results.

Author Contributions: C.-H.L. and Y.-H.H. conceived and designed the experiments; C.-H.L., C.-J.L. and Z.-H.Y. analyzed the data; C.-H.L. and C.-J.L. contributed reagents/materials/analysis tools; all authors wrote the paper.

Conflicts of Interest: The authors declare no conflicts of interest.

\section{References}

1. Brånemark, P.I.; Breine, U.; Adell, R.; Hansson, B.; Lindström, J.; Ohlsson, Å. Intra-osseous anchorage of dental prostheses: I. experimental studies. Scand. J. Plast. Reconstr. Surg. Hand Surg. 1969, 3, 81-100. [CrossRef]

2. Albrektsson, T.; Worthington, M.D.; Eriksson, D. The Long-Term Efficacy of Currently Used Dental Implants: A Review and Proposed Criteria of Success. Int. J. Oral Maxillofac. Implants 1986, 1, 11-25. [PubMed] 
3. Misch, C.E.; Perel, M.L.; Wang, H.L.; Sammartino, G.; Galindo-Moreno, P.; Trisi, P.; Schwartz-Arad, D. Implant success, survival, and failure: The International Congress of Oral Implantologists (ICOI) pisa consensus conference. Implant Dent. 2008, 17, 5-15. [CrossRef] [PubMed]

4. Berglundh, P.L.; Klinge, B. A systematic review of the incidence of biological and technical complications in implant dentistry reported in prospective longitudinal studies of at least 5 years. J. Clin. Periodontol. 2002, 29 (Suppl. 3), 197-212. [CrossRef] [PubMed]

5. Eckert, S.E.; Wollan, P.C. Retrospective review of 1170 endosseous implants placed in partially edentulous jaws. J. Prosthet. Dent. 1998, 79, 415-421. [CrossRef]

6. Aguirrebeitia, J.; Müftü, S.; Abasolo, M.; Vallejo, J. Experimental study of the removal force in tapered implant-abutment interfaces: A pilot study. J. Prosthet. Dent. 2014, 111, 293-300. [CrossRef] [PubMed]

7. López de Lacalle, L.N.; Rodriguez, A.; Lamikiz, A.; Celaya, A.; Alberdi, R. Five-axis machining and burnishing of complex parts for the improvement of surface roughness. Mater. Manuf. Process. 2011, 26, 997-1003. [CrossRef]

8. Kronstrom, M.; McGrath, L.; Chaytor, D. Implant dentistry in the undergraduate dental education program at Dalhousie University. Part 1: Clinical outcomes. Int. J. Prosthodont. 2007, 21, 124-128.

9. Tosches, N.; Brägger, U.; Lang, N. Marginal fit of cemented and screw-retained crowns incorporated on the Straumann (ITI) ${ }^{\circledR}$ Dental Implant System: An in vitro study. Clin. Oral Implants Res. 2009, 20, 79-86. [CrossRef] [PubMed]

10. Sung, S.F.; Hsieh, C.Y.; Kao Yang, Y.H.; Lin, H.J.; Chen, C.H.; Chen, Y.W.; Hu, Y.H. Developing a stroke severity index based on administrative data was feasible using data mining techniques. J. Clin. Epidemiol. 2015, 68, 1292-1300. [CrossRef] [PubMed]

11. Liu, K.E.; Lo, C.L.; Hu, Y.H. Improvement of adequate use of warfarin for the elderly using decision tree-based approaches. Methods Inf. Med. 2014, 53, 47-53. [CrossRef] [PubMed]

12. Sung, S.F.; Chen, K.; Wu, D.P.; Hung, L.C.; Su, Y.H.; Hu, Y.H. Applying natural language processing techniques to develop a task-specific EMR interface for timely stroke thrombolysis: A feasibility study. Int. J. Med. Inform. 2018, 112, 149-157. [CrossRef] [PubMed]

13. Bouchard, P.; Renouard, F.; Bourgeois, D.; Fromentin, O.; Jeanneret, M.; Beresniak, A. Cost-effectiveness modeling of dental implant vs. bridge. Clin. Oral Implants Res. 2009, 20, 583-587. [CrossRef] [PubMed]

14. Chiang, H.J.; Tseng, C.C.; Torng, C.C. A retrospective analysis of prognostic indicators in dental implant therapy using the C5.0 decision tree algorithm. J. Dent. Sci. 2013, 8, 248-255. [CrossRef]

15. Vazquez Alvarez, R.; Perez Sayans, M.; Gayoso Diz, P.; Garcia Garcia, A. Factors affecting peri-implant bone loss: A post-five-year retrospective study. Clin. Oral Implants Res. 2015, 26, 1006-1014. [CrossRef] [PubMed]

16. Chen, M.L.; Su, Z.Y.; Lo, C.L.; Chiu, C.H.; Hu, Y.H.; Shieh, T.Y. An empirical study on the factors influencing the turnover intention of dentists in hospitals in Taiwan. J. Dent. Sci. 2014, 9, 332-344. [CrossRef]

17. Whalen, S.; Pandey, G. A comparative analysis of ensemble classifiers: Case studies in genomics. In Proceedings of the 2013 IEEE 13th International Conference on Data Mining, Dallas, TX, USA, 7-10 December 2013; pp. 807-816.

18. Nanni, L.; Brahnam, S.; Ghidoni, S.; Lumini, A. Toward a general-purpose heterogeneous ensemble for pattern classification. Comput. Intell. Neurosci. 2015, 2015, 85. [CrossRef] [PubMed]

19. Sesmero, M.P.; Ledezma, A.I.; Sanchis, A. Generating ensembles of heterogeneous classifiers using stacked generalization. Wires Data Min. Knowl. 2015, 5, 21-34. [CrossRef]

20. Santos, P.; Maudes, J.; Bustillo, A. Identifying maximum imbalance in datasets for fault diagnosis of gearboxes. J. Intell. Manuf. 2018, 29, 333-351. [CrossRef]

21. Allum, S.R.; Tomlinson, R.A.; Joshi, R. The impact of loads on standard diameter, small diameter and mini implants: A comparative laboratory study. Clin. Oral Implants Res. 2008, 19, 553-559. [CrossRef] [PubMed]

22. Becker, S.T.; Beck-Broichsitter, B.E.; Rossmann, C.M.; Behrens, E.; Jochens, A.; Wiltfang, J. Long-term Survival of Straumann Dental Implants with TPS Surfaces: A Retrospective Study with a Follow-up of 12 to 23 Years. Clin. Implant Dent. Relat. Res. 2016, 18, 480-488. [CrossRef] [PubMed]

23. Dittmer, S.; Dittmer, M.P.; Kohorst, P.; Jendras, M.; Borchers, L.; Stiesch, M. Effect of implant-abutment connection design on load bearing capacity and failure mode of implants. J. Prosthodont. 2011, 20, 510-516. [CrossRef] [PubMed]

24. Theoharidou, A.; Petridis, H.P.; Tzannas, K.; Garefis, P. Abutment screw loosening in single-implant restorations: A systematic review. Int. J. Oral Maxillofac. Implants 2008, 23, 681-690. [PubMed] 
25. Lindhe, J.; Meyle, J. Group D of European Workshop on Periodontology. Peri-implant diseases: Consensus Report of the Sixth European Workshop on Periodontology. J. Clin. Periodontol. 2008, 35 (Suppl. 8), 282-285. [CrossRef] [PubMed]

26. Sham, A.; Cheung, L.; Jin, L.; Corbet, E. The effects of tobacco use on oral health. Hong Kong Med. J. 2003, 9, 271-277. [PubMed]

27. Ling, L.J.; Hung, S.L.; Tseng, S.C.; Chen, Y.T.; Chi, L.Y.; Wu, K.M.; Lai, Y.L. Association between betel quid chewing, periodontal status and periodontal pathogens. Oral Microbiol. Immunol. 2001, 16, 364-369. [CrossRef] [PubMed]

28. Galindo-Moreno, P.; Fauri, M.; Ávila-Ortiz, G.; Fernández-Barbero, J.E.; Cabrera-León, A.; Sánchez-Fernández, E. Influence of alcohol and tobacco habits on peri-implant marginal bone loss: A prospective study. Clin. Oral Implants Res. 2005, 16, 579-586. [CrossRef] [PubMed]

29. McDermott, N.E.; Chuang, S.K.; Woo, V.V.; Dodson, T.B. Complications of dental implants: Identification, frequency, and associated risk factors. Int. J. Oral Maxillofac. Implants 2003, 18, 848-855. [CrossRef] [PubMed]

30. Parein, A.M.; Eckert, S.E.; Wollan, P.C.; Keller, E.E. Implant reconstruction in the posterior mandible: A long-term retrospective study. J. Prosthet. Dent. 1997, 78, 34-42. [CrossRef]

31. Moy, P.K.; Medina, D.; Shetty, V.; Aghaloo, T.L. Dental implant failure rates and associated risk factors. Int. J. Oral Maxillofac. Implants 2005, 20, 569-577. [PubMed]

32. Manor, Y.; Oubaid, S.; Mardinger, O.; Chaushu, G.; Nissan, J. Characteristics of Early Versus Late Implant Failure: A Retrospective Study. J. Oral Maxillofac. Surg. 2009, 67, 2649-2652. [CrossRef] [PubMed]

(C) 2018 by the authors. Licensee MDPI, Basel, Switzerland. This article is an open access article distributed under the terms and conditions of the Creative Commons Attribution (CC BY) license (http:/ / creativecommons.org/licenses/by/4.0/). 